\title{
Resiliência organizacional: proposição de modelo integrado e agenda de pesquisa
}

\author{
HÉLIO ARTHUR REIS IRIgARAY \\ Fundação Getulio Vargas / Escola Brasileira de Administração Pública e de EMPresas, Rio de Janeiro - RJ, BRASIL \\ Kely Cesar Martins de Paiva \\ Universidade Federal de Minas Gerais / Faculdade de Ciências Econômicas, Belo Horizonte, MG - Brasil \\ Cristina Chaves Goldschmidt \\ Fundação Getulio Vargas / Escola Brasileira de Administração Pública e de EMPresas, Rio de Janeiro - RJ, BRASIL
}

\begin{abstract}
Resumo
A proposta deste ensaio teórico foi lançar luzes e sintetizar questões conceituais a respeito da resiliência no mundo do trabalho - ou seja, considerando trabalhadores e organizações -, propor um modelo integrado de análise. Para tanto, foi realizado um resgate histórico da discussão do constructo, suas especificidades no campo da Administração, o que inclui níveis de análise diferenciados. Após conceituar resiliência organizacional e considerando-se os elementos da resiliência nos níveis individual e sistêmico, assim como aspectos contextuais que permeiam as relações que se passam nos níveis micro e macro de análise, propôs-se um modelo integrado de análise de Resiliência Organizacional. A partir dele, traçou-se uma agenda de pesquisa que abraçou aspectos metodológicos e conexões conceituais e temáticas, a qual pode contribuir para o debate de um constructo que engloba processos altamente complexos, que envolvem níveis diferenciados de análise, e que estão submetidos a lógicas nem sempre claras e precisas, tanto para o indivíduo como para a organização, de modo amplo aqui considerados.
\end{abstract}

Palavras-chave: Resiliência. Resiliência organizacional. Resiliência individual. Resiliência sistêmica.

\section{Organizational resilience: a proposition of an integrated model and research agenda}

\begin{abstract}
This theoretical essay seeks to clarify and synthesize conceptual issues related to resilience in the labor market, as well as to propose an integrated analysis model taking into consideration workers and organizations. An historical review of the concept of resilience was conducted, observing its particularities in the field of Administration and including different levels of analysis. After conceptualizing Organizational Resilience, the study discussed the elements of resilience at the individual and systemic levels, as well as aspects of the context permeating the relationships at the micro and macro levels of analysis, proposing an integrated model of Organizational Resilience analysis. A research agenda is then proposed, embracing methodological aspects and conceptual and thematic connections, in order to contribute to the debate on resilience encompassing highly complex processes that involve different levels of analysis, and are subject to principles not always clear and precise, both for the individual and for the organization.
\end{abstract}

Keywords: Resilience. Organizational resilience. Individual resilience. Systemic resilience.

\section{Resiliencia Organizacional: propuesta de modelo integrado y agenda de investigación}

\section{Resumen}

El propósito de este ensayo teórico es arrojar luz y sintetizar cuestiones conceptuales sobre la capacidad de recuperación en el mercado laboral, es decir, teniendo en cuenta trabajadores y organizaciones, y proponer un modelo de análisis integrado. Para ello, se realizó un rescate histórico de la discusión del constructo, y de susespecificidades en el campo de la Administración, lo que incluye diferentes niveles de análisis. Después de la conceptualización de la resiliencia organizacional y considerando los elementos de la resiliencia en los niveles individual y sistémico, así como aspectos contextuales que permean las relaciones que tienen lugar en los niveles micro y macro de análisis, se propuso un modelo integrado de análisis de la Resiliencia Organizacional. A partir de este, hemos elaborado una agenda de investigación que abarcó aspectos metodológicos y conexiones conceptuales y temáticas, que pueden contribuir al debate de un constructo que abarque procesos de alta complejidad que implican diferentes niveles de análisis y que están sometidos a lógicas no siempre claras y precisas, tanto para el individuo como para la organización, aquí considerados de modo amplio.

Palabras clave: Resiliencia. Resiliencia organizaciona. Resiliencia individua. Resiliencia sistémica. 


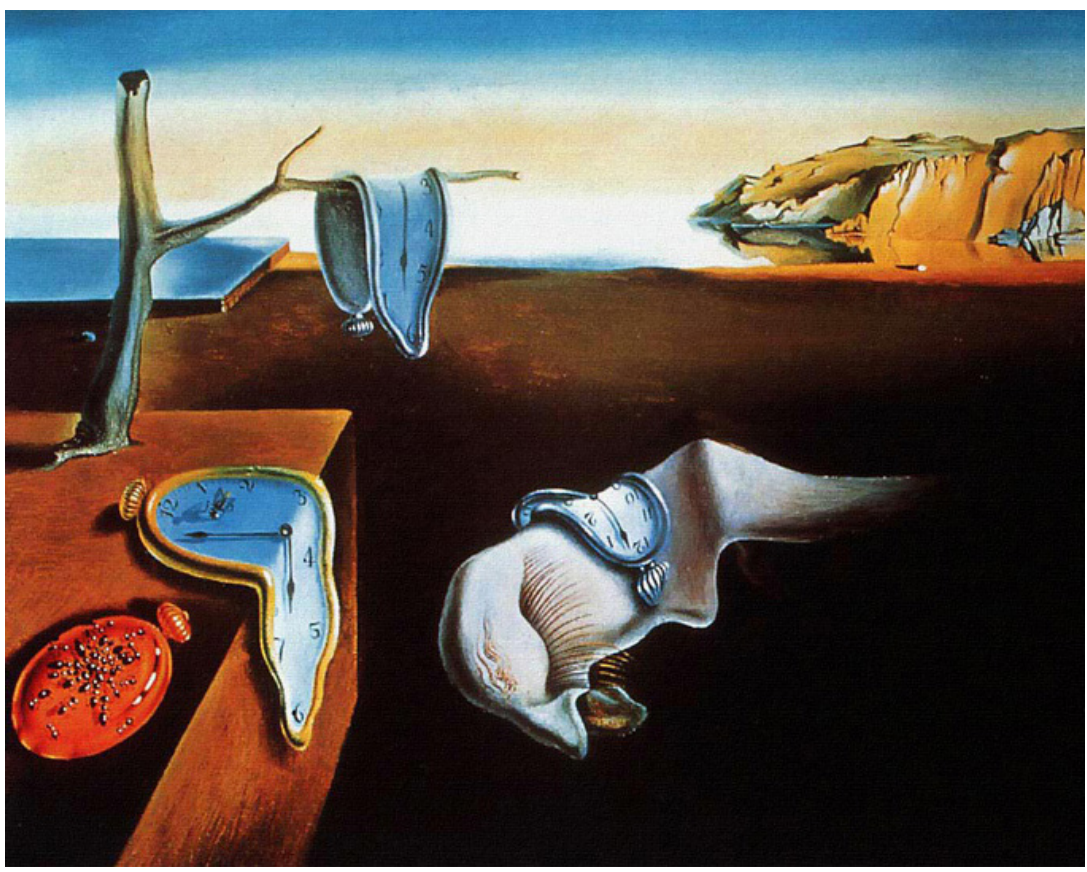

\section{INTRODUÇÃO}

Inicialmente importado da Engenharia de Materiais e com significados que se tangenciam em outros campos de saber, resiliência, no campo da Administração, é um constructo que tem sido sistematicamente utilizado e surge como produto da interação entre o sujeito ou o sistema e o meio em que está inserido, delineando duas perspectivas: a da resiliência das pessoas no ambiente organizacional (FLACH, 1991; CONNER, 1995; WEICK e SUTCLIFFE, 2001; DENHARDT e DENHARDT, 2010) e a da resiliência das organizações (HORNE e ORR, 1997; HAMEL e VALIKANGAS, 2003; SUTCLIFFE e VOGUS, 2003; LENGNICK-HALL, BECK e LENGNICK-HALL, 2011; BURNARD e BHAMRA, 2011).

Uma forte influência na compreensão desse constructo advém da Psicologia: Lengnick-Hall, Beck e Lengnick-Hall (2011) afirmam que, não obstante trabalhos acadêmicos na área de Administração envolvam discussões sobre resiliência, a maior parte da produção relacionada ao constructo pertence ao campo da Psicologia. Neste campo, Yunes e Szymanski (2005) atentam para o fato de que a definição de resiliência não é tão clara nem tão precisa quanto na Física ou na Engenharia. Segundo as autoras, não há como comparar coisas de naturezas diferenciadas, isto é, resiliência de materiais com resiliência de cunho psicológico (YUNES e SZYMANSKI, 2005).

A resiliência tem atraído a atenção do mercado e da academia há anos e, mesmo assim, uma definição comum ainda é evasiva. Enquanto a maioria dos autores concorda que se trata de uma capacidade de crescer e avançar em face de adversidades, muita ambiguidade continua a existir em torno dos processos subjacentes que compõem a resiliência. Nesse sentido, alguns autores têm defendido a necessidade de uma maior clareza no uso de definições a tal respeito (POLK, 1997; LUTHAR e CICCHETTI, 2000), o que evidencia a relevância de se compreender o constructo, sua evolução, aspectos significativos etc. no mundo do trabalho como premissa para a elaboração de proposições metodológicas, epistemológicas e praxeológicas que ampliem, de forma pragmática, as possibilidades de acesso, por indivíduos e organizações, a um repertório de respostas produtivas às adversidades experimentadas na contemporaneidade.

A proposta deste ensaio teórico, é lançar luzes e sintetizar tais questões conceituais, considerando o mundo do trabalho, ou seja, trabalhadores e organizações, e, propor um modelo integrado de análise que, por sua vez, enseje o traço de uma agenda 
de pesquisa que abrace aspectos metodológicos e conexões temáticas. Para tanto, será explicitado um resgate histórico da discussão do constructo, suas especificidades no mundo do trabalho, o que inclui níveis de análise diferenciados, proposição de um modelo integrado e de uma agenda de pesquisa.

\section{RESGATE DO HISTÓRICO DO CONSTRUCTO}

A resiliência pode ser entendida como uma característica de objetos/materiais, indivíduos, organizações e sistemas (DENHARDT e DENHARDT, 2010). No entanto, as formas como cada campo de saber (engenharia, física, psicologia, admininstração, economia) tem traduzido, definido e utilizado o conceito de resiliência são bastante distintas (DENHARDT e DENHARDT, 2010), brevemente descritas neste ensaio.

Na Engenharia e na Física, a concepção do termo resiliência ocorreu a partir de experimentos nos quais metais eram submetidos a pressões diversas (temperatura, força, etc.) a fim de determinar o grau de elasticidade que poderiam suportar sem serem destruídos. Tais estudos comprovaram que, cessada a pressão sobre o material, este retornava a sua condição inicial, mantendo suas propriedades. Assim, "[...] a capacidade do material estrutural suportar um impacto sem ficar deformado permanentemente depende de sua resiliência" (BEER e JOHNSTON, 1989, p. 522); ou seja, ela está relacionada à capacidade que a zona elástica de um material tem de voltar ao normal depois de cessada a fonte de energia que causa a deformação (BRANDÃO, MAHFOUD e GIANORDOLI-NASCIMENTO, 2011).

Então, o ponto comum do constructo, entre físicos e engenheiros, relaciona-se ao limite de elasticidade que um material apresenta.

No campo das Ciências Humanas, a resiliência apresenta polissemia, é concebida como uma trajetória, um contínuo, um sistema, um traço, um processo, um ciclo ou, ainda, uma categoria qualitativa (FLACH, 1980; RUTTER, 1985; JACELON, 1997; TUSAIE e DYER, 2004). Para Reich, Zautra e Hall (2010), a resiliência pode ser analisada em níveis diversos: dimensões básicas como a biológica, a cognitiva, a emocional, a comportamental; a perspectiva das fases da vida humana, a dimensão social e a organizacional ou da comunidade; e sob a ótica de aspectos étnicos e de diferentes dimensões culturais.

Alguns pesquisadores, em trabalhos sobre temas relacionados à infância, tópicos de desenvolvimento em psicologia e psiquiatria e temas relacionados à recuperação de sistemas naturais pós-estresses ambientais, tentam compreender como os indivíduos e os ecossistemas são capazes de ir e vir, desequilibrar-se e reequilibrar-se ou, termo bem comum, movimentar-se no esquema bounce back quando enfrentam uma adversidade (RUTTER, 1999; LUTHAR, CICCHETTI e BECKER, 2000; TUGADE e FREDRICKSON, 2004; DENHARDT e DENHARDT, 2010). Muitas vezes, eles recorrem a símiles a partir da constituição física de certo material para exemplificar e ilustrar as conclusões de seus estudos, mas não atribuem à Física, propriamente dita, o uso do termo resiliência.

Na Psicologia, o início da discussão do termo deu-se quase cinco décadas a partir de estudos sobre psicopatologias do desenvolvimento, na década de 1970, estendendo-se nos anos 1980 por pioneiros como E. James Anthony, Emory Cowen, Norman Garmezy, Lois Murphy, Michael Rutter e Emmy Werner (MASTEN e WRIGHT, 2010) - nessa perspectiva, invencibilidade e invulnerabilidade são termos precursores do termo resiliência.

No referido período, o fato de algumas pessoas permanecerem saudáveis apesar de expostas a severas adversidades chamou a atenção de pesquisadores americanos e ingleses (GARMEZY, MASTEN e TELLEGEN, 1984; RUTTER, 1985; 1987; 1999). Inicialmente elas foram chamadas de invulneráveis e o fenômeno, de invulnerabilidade, termo substituído por resiliência posteriormente. Rutter $(1985 ; 1987)$ e Garmezy $(1974)$, pioneiros no estudo da resiliência na Psicologia, explicam que invulnerabilidade passa uma ideia de resistência absoluta ao estresse e uma característica imutável; ela dá a entender que os indivíduos são intocáveis e não têm limites para suportar o sofrimento.

Outros importantes trabalhos marcam o início dos estudos sobre resiliência. Focalizam crianças expostas a múltiplos fatores de risco, como os longitudinais feitos por Werner e Smith (1992), que durou 32 anos, o de Rutter, ao longo de dez anos (de 1979 a 1989), além do trabalho do Minnesota Risk Research Project, conduzido por Garmezy (1974) e seus colegas (GARMEZY, MASTEN e TELLEGEN, 1984) durante 11 anos, de 1971 a 1982, dentre outros (GARMEZY, 1974). 
Os estudiosos supracitados e outros reconheceram a importância, a relevância e o significado de compreender a resiliência no processo de desenvolvimento humano, de compreender como pessoas que tinham tudo contra si alcançaram um desenvolvimento positivo. De um ponto de vista histórico, tais pesquisadores revelaram uma mudança de paradigma: de examinar fatores de risco que levavam a problemas psicossociais para a identificação de pontos fortes de um indivíduo que o conduziam a uma adaptação saudável em face de adversidades (BENSON, 1997).

Mais recentemente, a resiliência é definida como a capacidade de seguir em frente de maneira positiva, a partir de experiências adversas, negativas ou positivas, traumáticas ou estressantes (TUGADE e FREDRICKSON, 2004); é um conceito amplo que se refere a processos ou padrões de adaptação positiva e desenvolvimento em um contexto de risco e adversidade (LUTHAR, CICCHETTI e BECKER, 2000; ZAUTRA, HALL e MURRAY, 2010). Nas palavras de Masten e Wright (2010, p. 215) "[...] um conceito amplo que geralmente se refere a adaptação positiva em qualquer tipo de sistema dinâmico que esteja sob desafio ou ameaça".

Embora a visão de resiliência como invulnerabilidade, que marcou os estudos iniciais, seja alvo de pesquisas mais recentes, estas têm indicado que não há uma quantidade fixa de resistência por parte do indivíduo, ela varia de acordo com as circunstâncias (RUTTER, 1985); e, também, que a resiliência, ou resistência ao estresse como alguns denominam, é relativa, sustentando-se em bases tanto constitucionais quanto ambientais, reforçando a constatação de que resiliência e invulnerabilidade não são termos equivalentes (ZIMMERMAN e ARUNKUMAR, 1994). No entanto, esta visão inicial de invulnerabilidade às adversidades ainda vem orientando uma parte da produção científica de muitos pesquisadores (YUNES, 2003).

No que diz respeito à resiliência humana, embora a habilidade de crescer e seguir em frente diante do infortúnio seja o ponto sobre o qual a maioria dos autores concordam, muita ambiguidade continua a existir em torno das características e processos subjacentes compreendidos na resiliência, como, por exemplo, se qualidades de resiliência são aprendidas ou são parte da natureza genética de um indivíduo, sendo este um debate bastante comum (RICHARDSON, 2002).

Assim, alguns elementos são chave para que se possa aprofundar o conceito de resiliência, como também contribuir para a evolução desse constructo, como é o caso dos fatores de risco, adversidade, estresse, fatores de pressão, características da resiliência e vulnerabilidade - expostos a seguir.

\section{FATORES DE RISCO, ADVERSIDADE E ESTRESSE}

A definição base da resiliência traz a questão da adaptação do indivíduo frente a situações de adversidade ou de estresse. Risco, adversidade e estresse são termos mencionados frequentemente nas conceituações de resiliência. Há certa dificuldade em distingui-los, uma vez que os três se referem a experiências negativas. Experiências de vida negativas são inevitáveis para qualquer indivíduo e um evento pode ser enfrentado como perigo por um indivíduo e, para outro, representar apenas um desafio. O que significa dizer que a visão subjetiva de um indivíduo em determinada situação - ou seja, sua percepção, interpretação e sentido atribuído ao evento estressor - é que o classificará, ou não, como adversidade e determinará a condição e a intensidade do estresse percebido. No que diz respeito à apreciação do que é adversidade e do estresse que ela pode causar, destaca-se questão dos níveis de exposição e dos limites individuais de cada um (YUNES e SZYMANSKI, 2001).

Fatores de risco são aqueles presentes no ambiente econômico, psicológico e familiar que possuem grande probabilidade de causar danos sociais evidentes; é um termo ainda aplicado para agrupar eventos que englobam, entre outros, ameaças, sofrimentos, perigos e rupturas externas; são de forma genérica denominados por diversos autores "experiências estressantes" ou "condições adversas" ou "adversidades" (TABOADA, LEGAL e MACHADO, 2006).

Fatores de risco podem ser crônicos ou agudos: condições de pobreza, rupturas na família, vivência de algum tipo de violência, experiência de doença no próprio indivíduo ou na família e perdas importantes são alguns exemplos.

Adversidade é o termo associado a um estado de angústia ou sofrimento derivado de infortúnio, trauma, dificuldade, mudança, um acontecimento trágico ou a um evento positivo (RUTTER, 1999; LUTHAR, CICCHETTI e BECKER, 2000; TUGADE e FREDRICKSON, 2004; DENHARDT e DENHARDT, 2010).

Estresse pode ser entendido como um conjunto de alterações em um organismo em resposta a um determinado estímulo que o coloque sob tensão. Diante da tensão, uma série de respostas psicofisiológicas, que tem por função atuar no evento 
causador de estresse e restabelecer o equilíbrio dinâmico do organismo, é gerada pelo indivíduo, o que coloca o estresse na condição de uma resposta adaptativa, pois estimula o indivíduo para a ação. Não há como prever a resposta que um indivíduo produzirá frente ao estresse. A reação dependerá diretamente dele, do modo como lida e significa o mundo em que vive, bem como das variáveis do contexto (TABOADA, LEGAL e MACHADO, 2006).

Abordagens do estresse como processo e como estado são levantadas por Limongi-França e Rodrigues (2005, p. 32-33): “O stress como processo é a tensão diante de uma situação de desafio por ameaça ou conquista. O stress como estado é o resultado positivo (eutress) ou negativo (distress) da tensão realizada pela pessoa". Essa perspectiva coaduna-se com a compreensão das diferenças comportamentais das pessoas em face de situações adversas. No campo das organizações, três abordagens podem ser consideradas na compreensão do fenômeno do estresse ocupacional, quais sejam: na primeira, o estresse é compreendido como variável dependente, o foco está na resposta do indivíduo ao fator perturbador; na segunda, como variável independente, enfatiza-se o estímulo externo ao qual o indivíduo está sujeito; e, na terceira, de natureza interacionista, as luzes concentram-se no modo como ele percebe e reage às situações que vivencia no seu cotidiano (TRAVERS e COOPER, 1996). Predomina, nos estudos sobre esta temática específica, essa terceira abordagem (TRAVERS e COOPER, 1996), o que também se verifica no Brasil (ANDRADE, GUIMARÃES e ASSIS, 2010; PAIVA, DUTRA, BARROS et al., 2013; PAIVA, GOMES, HELAL, 2015).

Tal perspectiva vai ao encontro da premissa da resiliência segundo a qual pessoas, assim como qualquer sistema, possuem recursos ou ativos que as ajudam a sobreviver a adversidades e a lidar com o estresse causado por elas. Respostas de adaptação ao estresse podem ser promovidas por meio do reforço de fatores de proteção, de modo que a manutenção ou o desenvolvimento desses fatores pode indicar adaptação positiva em face da adversidade.

\section{FATORES DE PROTEÇÃo, CARACTERÍSTICAS DE RESILIÊNCIA E VULNERABILIDADE}

Com o intuito de perseguir de forma sistemática a identificação de fatores que diferenciavam as crianças que se adaptavam de forma saudável daquelas que demonstravam um grau menor de ajustamento ou adaptação, as pesquisas que sucederam o trabalho de Emmy Werner (1992) expandiram-se, incluindo múltiplas condições adversas, como desvantagem socioeconômica e os riscos a ela associados (WERNER e SMITH, 1992; RUTTER, 1999), maus tratos (BEEGHLY e CICCHETTI, 1994; CICCHETTI e ROGOSCH, 1997) e eventos catastróficos (O'DOUGHERTY-WRIGHT, MASTER e HUBBARD et al., 1997). Tais pesquisas avançaram sobre a identificação de fatores que agiam para viabilizar uma resposta de adptação saudável; em outras palavras, identificação dos fatores de proteção.

Embora encontrada em um estudo sobre maus tratos a crianças, é muito clara a definição de Deslandes e Junqueira (2003) sobre fatores de proteção como o conjunto de influências que modificam e melhoram a resposta de um indivíduo quando exposto a algum perigo, risco ou ameaça que predispõe a um resultado de não adaptação. Esta relação entre fatores de proteção e situações de adversidade ou fatores de risco é esclarecida por Tusaie e Dyer (2004, p. 4), ao definirem fatores de proteção como aqueles que são capazes de proteger os indivíduos em situação de risco de seus efeitos negativos, ou seja, "as interações entre risco e fatores de proteção num nível intrapessoal e ambiental são integradas para a definição de resiliência".

Características de resiliência vêm sendo referidas como fatores de proteção ou ativos de desenvolvimento (RICHARDSON, 2002). Carmello (2008) afirma que, em $80 \%$ dos estudos sobre resiliência, é possível encontrar um conjunto de características ou atributos inerentes a pessoas resilientes. Segundo o autor, embora todos os indivíduos tenham tais características, o que importa não é possuir o conjunto de características, mas como ele se manifesta no momento adequado.

Carmello (2008, p. 76) elenca sete características que são ativadas nos enfrentamentos e situações adversas, possibilitando melhores resultados: protagonismo, criatividade, gosto por mudanças, autoeficácia elevada, senso de humor e equilíbrio emocional.

Protagonista é o indivíduo que se posiciona como corresponsável e peça-chave para o alcance dos resultados (CARMELLO, 2008). Assim conceituado, o protagonismo aproxima-se do conceito de lócus de controle, usualmente apresentado como uma característica de personalidade que influencia o grau de propensão ao estresse do indivíduo. Trata-se de um contínuo em que os polos podem ser o lócus de controle externo (pessoas que se sentem passivas frente ao meio externo) e lócus de 
controle interno (pessoas que agem ativamente no meio que as rodeia, influenciando-o) - sendo que a proximidade a este último polo sinaliza menor propensão ao estresse (ROTTER, 1966).

Reivich e Shatté (2002) relatam que sete fatores centrais constituem a resiliência, dentre eles a regulação das emoções, caracterizado por esses pesquisadores como a capacidade de manter-se calmo diante das adversidades. Entendem os autores que a autorregulação é fundamental para que vínculos mais positivos tanto na vida pessoal como no trabalho sejam estabelecidos, bem como para manter a saúde física. Fortemente relacionado ao controle das emoções está o controle de impulsos que, associado ao comportamento de agir impulsivamente, compromete o ajuste das emoções.

Além dos dois fatores já mencionados, Reivich e Shatté (2002) ainda enumeram: otimismo, autoeficácia, análise causal, empatia e exposição.

Para Yunes e Szymanski (2001), a resiliência é o produto final da combinação e acúmulo dos fatores de proteção. Em contrapartida, Tusaie e Dyer (2004) apontam que, embora inúmeros estudos já tenham demonstrado que existe uma correlação entre a presença da resiliência e de fatores de proteção, não está claro o modo como os fatores de proteção interagem com a pessoa que demonstra resiliência, já que um mesmo indivíduo pode apresentar resiliência diante de determinadas adversidades e ter maior probabilidade de resultados negativos diante de outras, ou seja, pode apresentar vulnerabilidades.

Na literatura de Psicologia, a vulnerabilidade refere-se a predisposições a desordens ou à susceptibilidade ao estresse (YUNES e SZYMANSKI, 2001), ou ao aumento da probabilidade de resultados negativos diante da exposição ao risco (GARCIA, 2001; GUZZO e TROMBETA, 2002).

Da mesma forma que fatores de proteção, vulnerabilidade está também relacionada com as adversidades, ou situações de risco. Assim, identificar se um indivíduo se apresenta vulnerável ou não é sempre uma avaliação situacional, eis que implica conhecer as suas características pessoais, as do ambiente em que está inserido e, principalmente, os fatores de risco e de proteção envolvidos (TABOADA, LEGAL e MACHADO, 2006).

\section{RESILIÊNCIA NO CAMPO DA ADMINISTRAÇÃO: REVISITANDO A LITERATURA}

No campo da Administração, observam-se dois níveis de análise da resiliência: das pessoas no ambiente organizacional e das organizações. $O$ estudo da resiliência neste campo permite a exploração de fatores que impactam diretamente o desempenho das organizações em seus (macro) ambientes e das pessoas em seus (micro e meso) ambientes profissionais, influenciando resultados de curto e longo prazos das organizações.

Considerando que a literatura sobre resiliência organizacional ainda é pouco desenvolvida, Denhardt e Denhardt (2010) recomendam considerar dois aspectos.

O primeiro trata da perspectiva da qual os autores do assunto estão partindo, se da psicológica (MALLACK, 1998) ou dade sistemas (HORNE, 1997); e se a abordagem foca na reação a circunstâncias pontuais e de grandes proporções (LENGNICK-HALL, BECK e LENGNICK-HALL, 2011) ou na capacidade de adaptação de longo prazo (HAMEL e VALIKANGAS, 2003), o que Denhardt e Denhardt chamam de resiliência cotidiana (everydayresilience) (DENHARDT e DENHARDT, 2010, p. 336).

O segundo concentra-se no foco do autor: se é sobrevivência (LISSACK e LETICHE, 2002) ou inovação ou construção de capacitação (SUTCLIFFE e VOGUS, 2003; HAMEL e VALIKANGAS, 2003; LENGNICK-HALL, BECK e LENGNICK-HALL, 2011).

A presença de adversidades no ambiente organizacional demanda das pessoas ações de resposta, isto é, como lidar de forma positiva com a adversidade: como lidar interna/subjetivamente e externa/objetivamente com o estresse causado pela adversidade, como perceber e avaliar fatores de risco presentes na adversidade, como melhor se adaptar a um eventual novo contexto trazido pela adversidade, como aprender com a experiência adversa.

Em um contexto organizacional, Luthans (2002, p. 702) define resiliência humana como "[...] a capacidade, que pode ser desenvolvida, de se recuperar das adversidades, conflitos e de falhas, ou até mesmo, em face de eventos positivos, que representam progresso e aumento da responsabilidade". 
Para Jackson, Firtko e Edenborough (2007, p. 3), “[...] adversidade no ambiente de trabalho pode ser vista como qualquer situação negativa, estressante, traumática ou difícil ou episódio de dificuldade que seja encontrado no ambiente ocupacional”.

Denhardt e Denhardt (2010, p. 333) asseveram que "[...] resiliência envolve a habilidade de se adaptar de forma criativa e construtiva à mudança, e mudança é uma constante na vida organizacional de hoje". Para esses autores, a resiliência é definida como a habilidade de se recuperar (bounce back) de adversidades (que variam de desastres a disputas de poder, passando por crises de turnover), de forma que a organização se torne mais flexível e mais preparada para se adaptar a adversidades futuras.

Desse modo, a resiliência, no nível individual, é uma qualidade e uma capacidade que pessoas, enquanto trabalhadoras, líderes e gestoras em organizações, deveriam procurar desenvolver a qualquer tempo (não só diante de desastres ou crises externas e internas), implicando que compreender o indivíduo resiliente pode fornecer bases para definir organizações resilientes, já que tanto as interações entre os indivíduos como suas ações isoladas alicerçam a capacidade coletiva de resiliência de uma organização (LENGNICK-HALL, BECK e LENGNICK-HALL, 2011).

Importante esclarecer que se percebe um degrau entre resiliência do indivíduo e resiliência da organização, assim como já foi observado entre aprendizagem individual e organizacional, afinal, a aprendizagem individual pode ser "contestada" de vários ângulos dentro das organizações - politicamente, ideologicamente, pragmaticamente etc. -, como apontaram Rodrigues, Child e Luz (2004). Do mesmo modo, Paiva (2013) observou esse degrau entre competências profissionais e competências organizacionais. Em síntese, o nível organizacional de análise compreende mais que a soma das contribuições das "partes individuais"; desse modo, a resiliência organizacional não é meramente a junção das resiliências individuais; para além disso, ela compreende tais contribuições individuais agregadas por um sistema ou conjunto de processos que permitam e promovam sua efetivação no dia a dia. Para sustentar esse argumento, duas questões carecem de aprofundamento: a da resiliência humana e a da resiliência organizacional.

\section{SOBRE RESILIÊNCIA INDIVIDUAL}

Em direção a uma concepção para além da díade risco-proteção, Masten (2001), Luthar, Cicchetti e Becker (2000) e Waller (2001) tratam do fenômeno resiliência humana como processo dinâmico, multidimensional ou ecossistêmico.

Nesse sentido, cabe ressaltar que as concepções de resiliência foram mudando, ao longo dos anos, de uma perspectiva de atributo absoluto e global para uma perspectiva de uma capacidade relativa e circunstancial. Desse modo, considera-se que há duas condições críticas implícitas na noção de resiliência: exposição à adversidade (ameaça/risco ou evento positivo) e alcance de adaptação positiva. Por definição, a resiliência é posicionada de forma interdependente da adversidade, ou seja, para demonstrar resiliência é preciso primeiro encontrar adversidade ou desafio (CHARNEY, 2004; ZAUTRA, HALL e MURAY, 2010; MASTEN e WRIGHT, 2010; KENT e DAVIS, 2010).

Para Reich, Zautra e Hall (2010), embora a resiliência se apresente sob definições e caracterizações eivadas de certa variação, há dois temas dominantes que são centrais ao conceito: (1) como uma resposta a eventos estressores ou adversidades, a resiliência foca na recuperação (recovery), que é a habilidade de se recuperar do estresse, a capacidade de reaver o equilíbrio (físico e psíquico) rapidamente, retornando ao equilíbrio, ao estado saudável ou produtivo (MASTEN, 2001); e (2) como um resultado da adaptação bem sucedida à adversidade, implica a continuidade da trajetória de recuperação, gerando sustentabilidade (sustainability) do equilíbrio saudável, que permite a melhoria das capacidades funcionais para lidar com estresse e/ou adversidade futuros, e continuar seguindo em frente em face da adversidade (BONNANO, 2004), como em um ciclo virtuoso.

De acordo com Denhardt e Denhardt (2010), indivíduos não sobrevivem a adversidades simplesmente retornando ao seu estado anterior. Na verdade, a chave para a resiliência psicológica é a capacidade de se adaptar, aprender e mudar, e se tornar mais resiliente. Assim, a resiliência vai muito além de resistir ao estresse, recuperar-se, "saltar para trás", ou movimentar-se no bounce back: a questão do ajustamento ou enfrentamento é central e será aprofundada adiante.

Também vale a pena mencionar que fatores individuais (porque as pessoas diferem em suas capacidades internas), sociais, culturais e ambientais influenciam a capacidade global de um indivíduo para se recuperar. 


\section{RESILIÊNCIA: DICOTOMIAS OU CONTÍNUOS?}

Há muitos anos, a resiliência foi discutida como um traço de personalidade (BLOCK e BLOCK, 1980) e, em um esforço para "[...] descrever traços de personalidade que facilitem a adaptação flexível e engenhosa a fatores de estresse, a modulação de impulsos e a adaptação a situações novas" (SKODOL, 2010, p. 115), o conceito de ego-resiliency foi desenvolvido abrangendo traços como curiosidade, humor, sociabilidade e presença e insight. No âmbito das teorias de resiliência como um traço (de personalidade), destaca-se a atenção dada à ideia de que combinações de características físicas e psicológicas, incluindo química corporal e fatores de personalidade, fornecem aos indivíduos os skills para serem resilientes (JACELON, 1997; FLACH, 1991).

Os termos ego-resiliency e resiliência se diferenciam em duas dimensões significativas: uma característica de personalidade do indivíduo e um processo de desenvolvimento dinâmico (incluindo o resultado resiliente como fator-chave para a sustentabilidade). Mesmo assim, ego-resiliency pode estar frequentemente implicado no processo de resiliência (LUTHAR, CICCHETTI e BECKER, 2000).

Para descobrir o que levou um indivíduo ou um sistema (individual) a um resultado resiliente, optar por um modelo causal com base em traço de personalidade é uma escolha limitada, dado que o conceito de imutabilidade subjacente ao de traço diminui, restringe a capacidade dinâmica dos sistemas de aprenderem a se adaptar de novas formas (MASTEN e WRIGHT, 2010). Além do que, a resiliência emerge de vários processos e interações que vão além do corpo humano e incluem relacionamentos interpessoais e contexto social para o alcance de adaptação positiva.

Ainda na abordagem da resiliência como um processo que resulta em adaptação positiva, Carver (1998) faz uma clara distinção entre resiliência, como um retorno ao nível de funcionamento anterior, ou seja, recuperação ou bounce back, e superação, como uma movimentação para um nível superior de funcionamento após um evento estressante.

Nas concepções de resiliência representativas do sentido de superação, que incluem Grotberg (1999; 2005; 2006), Carver (1998), Waller (2001), entre outros, o termo adaptação positiva integra grande parte das definições do constructo. As definições no sentido de superação descrevem claramente um processo no qual ocorre o enfrentamento de adversidades que são superadas e o caráter fortalecedor dessa experiência.

Assim sendo, a dicotomia (ou contínuo) conformidade versus superação merece aprofundamento no que tange à adaptação positiva.

Deslandes e Junqueira (2003), em um estudo que pretendeu identificar polarizações do conceito de resiliência, observaram duas maneiras diferentes de se conceber a resiliência no que diz respeito à adaptação. Junto com outros dois eixos que indicavam polarizações do conceito - inato versus adquirido e permanente versus circunstancial -, o eixo adaptação versus superação separa conceitos que enfocam adaptação dos indivíduos frente a traumas e adversidades - como o desenvolvimento de comportamentos adaptados às expectativas sociais (adaptação), ou seja, definições de resiliência que têm um sentido de ajustamento passivo às normas sociais ; e conceitos que enfocam o sentido de superação do trauma vivido que é elaborado simbolicamente (superação).

No sentido de superação, a adaptação positiva é o resultado de um processo em que existe a recuperação da homeostase (equilíbrio), e esta recuperação pode levar a um resultado de superação do indivíduo em relação à adversidade enfrentada, quando ele aprende com a experiência adversa e se fortalece.

No sentido de conformidade, a adaptação positiva pode variar de acordo com fatores culturais e sociais, dado um determinado período de tempo, e pode não exigir a exposição a uma experiência de adversidade. Luthar e Cicchetti (2000) indicam que a adaptação positiva é geralmente definida em termos de competência para manifestar comportamento social ou sucesso em tarefas que envolvem o desenvolvimento a partir de experiências adversas anteriores.

A adaptação positiva pode ser identificada no momento em que o indivíduo consegue alcançar expectativas sociais, vencendo a adversidade e se desenvolvendo -se a partir dela, ou quando não apresenta sinais de desajuste (INFANTE, 2005).

Infante (2005), no entanto, chama atenção para questões que não podem deixar de ser levantadas quando se trabalha com uma definição de resiliência que carrega essa ideia de adaptação (manifestação de comportamento social conforme), diante do caráter ideológico que se liga à ideia de adaptação que está associada ao desenvolvimento normal e às expectativas de 
uma sociedade. Para a autora, é preciso questionar: o que define o que é normal? Quem define? Quais seriam os parâmetros de avaliação para um desenvolvimento normal?

Para Melillo (2004), associar a resiliência à adaptação positiva parece implicar uma desconsideração de que o sujeito é um agente ativo na sociedade e pode, consequentemente, transformá-la. Segundo esse autor, se a resiliência é pensada em termos de adaptação positiva nos contextos dos regimes totalitários que vigoraram e vigoram na América do Sul, ela pode significar apenas uma sobrevivência subjugada.

Galende (2004), em concordância com a abordagem de Melillo (2004), aponta que a adaptação como sinal de submissão a uma dada realidade não deve ser considerada resiliência. Em complemento ao pensamento de Galende (2004), para Tavares (2001), na sociedade emergente, a resiliência deve ser construída no sentido de tornar as pessoas mais fortes e mais equipadas para poderem intervir socialmente e não as tornando mais insensíveis, passivas e conformadas.

Neste sentido, Yunes e Szymanski (2001, p. 35) referem-se a "resiliência performativa", que é um conceito construído por Martineau (1999), definida como "[...] conformidade às normas sociais, sucesso acadêmico e empatia pelos outros, porém manifestos apenas com o objetivo de agradar ou enganar" (YUNES e SZYMANSKI, 2001, p. 35). Manifestações de conformidade às vezes ocorrem em troca de um "preço" demasiado alto para a saúde mental de um indivíduo, que pode aparentar estar muito bem em relação a algo que teve que enfrentar em sua vida ou já enfrentou, mas, na verdade, sua superação é apenas aparente.

Outras concepções de adaptação são relacionadas à resiliência, como a piagetiana, segundo a qual o indivíduo desenvolve-se graças a processos sucessivos de adaptação a situações novas. Estes processos incluem os mecanismos de assimilação e acomodação (PIAGET, 1964; 1983; 1987). Piaget (1964) explica que a adaptação se define pelo equilíbrio entre a assimilação e a acomodação, o que reflete o processo de ajustamento ou enfrentamento (coping).

\section{COPING, ENFRENTAMENTO OU AJUSTAMENTO}

Os estudos e análises sobre coping têm muito a contribuir para a formulação teórica e operacional da resiliência. Na perspectiva de um processo dinâmico em que o resultado é a adaptação, o ajustamento ou enfrentamento, coping é um conceito inter-relacionado à resiliência, que pode ensejar ambiguidade conceitual (LAZARUS e FOLKMAN, 1984; SKODOL, 2010). Embora as bases conceituais deste conceito sejam muito parecidas com as da resiliência, coping e resiliência não são sinônimos.

A literatura apresenta modelos diferentes de coping, mas coping é geralmente definido como o "[...] conjunto das estratégias utilizadas pelas pessoas para adaptarem-se a circunstâncias adversas ou estressantes" (ANTONIAZZI, BANDEIRA e DELL'AGLIO, 1998, p. 273).

Lazarus e Folkman (1984), precursores no estudo do coping, apresentam uma definição que permite o seu entendimento como uma ação intencional, eis que esta definição é embasada nas "[...] constantes mudanças cognitivas e comportamentais na tentativa de administrar demandas específicas, internas e/ou externas, que são avaliadas pelo sujeito como excedendo ou sobrecarregando os recursos pessoais" (LAZARUS e FOLKMAN, 1984, p. 141).

Para esses autores, o coping é uma estratégia e não um estilo de personalidade.

[...] o foco de atenção está no que a pessoa está fazendo ou pensando no momento atual, presente, em contraste com o que a pessoa habitualmente faz, fazia ou deveria fazer, que é o foco das teorias relacionadas a traços de personalidade. Pensamentos ou ações de coping são sempre encaminhados para condições particulares. (LAZARUS e FOLKMAN, 1984, p. 142).

O que significa dizer que as estratégias podem mudar de momento para momento, durante os estágios de uma situação estressante, bem como durante os estágios de desenvolvimento do indivíduo, ou mesmo da sua carreira, pessoal ou no âmbito de uma organização. Coping envolve respostas cognitivas, na medida em que se refere a pensamentos específicos, respostas comportamentais e respostas emocionais que uma pessoa usa para administrar demandas internas e externas de situações avaliadas como estressantes, de modo a se proteger de dano psicológico. 
No entanto, o coping pode ou não ser consistente conforme as situações estressantes ou papéis funcionais (SKODOL, 2010) e é caracterizado como um esforço de pensamento ou ação/comportamento para gerir ou superar situações estressantes (LAZARUS e FOLKMAN, 1984). Coping pode ser uma parte do processo de resiliência.

Coping é um mecanismo que gera um resultado imediato ou de curto prazo como uma resposta a um estressor, enquanto resiliência requer tempo para ser desenvolvida (SKODOL, 2010). Enquanto o coping foca a forma, a estratégia utilizada para lidar com a situação, independentemente do resultado obtido, a resiliência concentra sua atenção no resultado da estratégia utilizada. O resultado resiliente seria a adaptação positiva do indivíduo, no sentido de bem sucedida, frente à adversidade (SKODOL, 2010).

Richardson, Neiger, Jensen et al. (1990, p. 34) definem resiliência como “[...] o processo de lidar com eventos de vida perturbadores, estressantes ou desafiadores de forma que propicie ao indivíduo habilidades de proteção e enfrentamento adicionais, em relação àquelas presentes no momento anterior à ruptura causada pelo evento" e propõem um processo de acesso a qualidades de resiliência como uma função de escolha, consciente ou inconsciente. Eles apresentam resiliência como uma estrutura simples e linear que retrata um indivíduo ou um grupo passando por estágios de homeostase biopsicoespiritual (biopsychospiritual), interações com eventos de vida, ruptura, prontidão para a reintegração e a escolha dentre a reintegração resiliente, o retorno a homeostase ou a reintegração com perda.

A reintegração com perda (RICHARDSON, 2002) revela o "preço" demasiado alto para a saúde mental de um indivíduo, de que trata também a resiliência performativa (MARTINEAU, 1999; YUNES e SZYMANSKI, 2001), e seu sentido de "ajustamento social" pode produzir pessoas "adaptadas" vivendo em um silencioso desespero ou ainda pessoas adaptadas, mas "não adaptáveis", porque implica uma conformidade a certas condições e valores da sociedade, mas não implica necessariamente saúde psicológica, conforme discutido por Block e Kremen (1996) sobre o conceito de adaptação.

Richardson (2002, p. 312) explica, sobre o estágio de reintegração disfuncional, que "[...] a reintegração disfuncional ocorre quando as pessoas recorrem a substâncias, comportamentos destrutivos ou outros meios para lidar com eventos da vida. A maioria das pessoas que se reintegram de forma disfuncional tem pontos cegos em suas habilidades introspectivas e necessitam de terapia para preencher os buracos".

O modelo mostra que as pessoas, ou por rupturas planejadas (casamento, gravidez, mudança de emprego etc.) ou reagindo a eventos da vida, têm a oportunidade de escolher, de forma consciente ou inconsciente, os resultados das rupturas. No modelo, o estágio da reintegração resiliente refere-se ao processo reintegrativo que resulta em crescimento, maior conhecimento, maior autoconhecimento e fortalecimento das qualidades de resiliência. A reintegração resiliente de Richardson (2002) implica, também, superação, conforme proposto por Carver (1998). A Figura 1 permite visualizar tais elementos e relações. 
Figura 1

\section{Modelo de Resiliência}

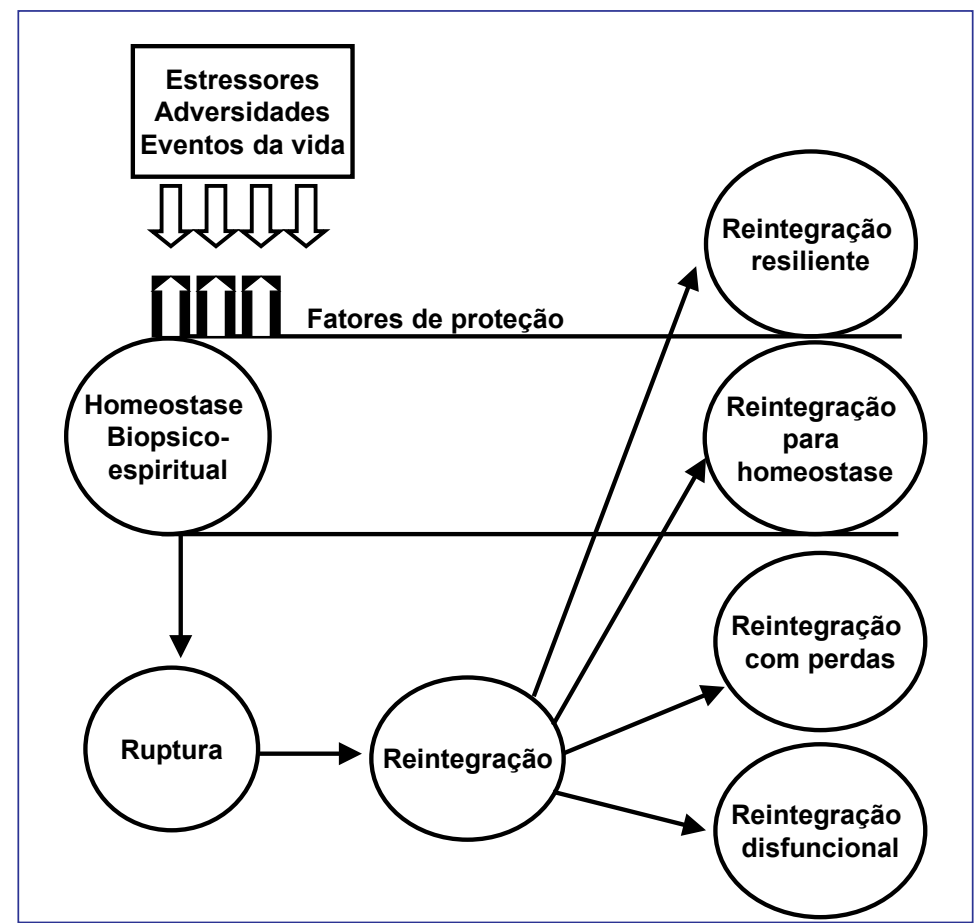

Fonte: Richardson, 2002, p. 311.

Considerando a perspectiva de processo e o caráter contextual da resiliência, chama-se atenção, nesta reflexão, para peculiaridades do trabalho do sujeito, quando do exercício de função gerencial, já que, em posição formal de poder, o desempenho visa atender interesses e resultados diferenciados dos subordinados. Do gestor espera-se uma variedade de comportamentos e resultados, muitas vezes contraditórios, o que caracteriza seu trabalho como fragmentado e ambíguo (HILL, 1993; MOTTA, 2007; DAVEL e MELO, 2005). A partir do entendimento de que o trabalho do gestor é alcançar efetividade por meio de seus subordinados, a complexidade da função se eleva, pois o nível de dependência de terceiros é crucial para o alcance de seus fins, independentemente da forma como ele é percebido, ou seja, como a "mola mestra" do fazer na organização (perspectiva técnica), como um elemento mediador de conflitos (perspectiva política), como um reprodutor da lógica do capital (perspectiva crítica) ou como a soma de todas as anteriores (perspectiva praxeológica) (REED, 1997).

Assim sendo, o trabalhador no exercício da função gerencial pode facilitar, ou dificultar, a resiliência de terceiros com os quais trabalha, tanto informalmente no cotidiano das práticas de trabalho, como formalmente por meio dos processos que compõem o sistema organizacional. A junção desses dois elementos, pessoas e processos, é alvo clássico das iniciativas de estudo no campo da gestão, pois da sua combinação pode-se transmutar para um nível mais macro de análise que, no caso deste ensaio, refere-se ao que vem sendo chamado de resiliência organizacional.

\section{SOBRE RESILIÊNCIA ORGANIZACIONAL}

Autores como Horne (1997), Horne e Orr (1997), Mallack (1998) e Sutcliffe e Vogus (2003) atribuem à resiliência organizacional uma definição focada na capacidade de "bouncing back", enfatizando mecanismos de coping organizacional que levem ao restabelecimento da situação anterior, o que leva a organização a concentrar esforços apenas "[...] para estabelecer um 
forte ajuste entre a empresa e uma nova realidade enquanto, ao mesmo tempo, evita ou limita comportamentos disfuncionais ou regressivos" (LENGNICK-HALL, BECK e LENGNICK-HALL, 2011, p. 244).

Em outra perspectiva, a resiliência organizacional é vista como superação, vai além da recuperação e inclui o desenvolvimento de novas capacidades e a expansão de habilidades que permitem a exploração de oportunidades e a construção de competências para lidar com adversidades futuras (COUTU, 2002).

Coutu (2002) e Hamel e Valikangas (2003) contribuem para a construção de uma definição de resiliência organizacional como a habilidade de uma organização em desenvolver respostas situacionais a rupturas que representem ameaças potenciais à sua sobrevivência, que possibilitem, na verdade, que a organização capitalize desenvolvimento em tais situações, engajando-se em atividades transformadoras e restauradoras de sua capacidade responsiva.

A literatura sobre sistemas socioecológicos aponta que, embora seja uma propriedade emergente de sistemas adaptativos complexos e esteja ligada a sua capacidade de resposta ao ambiente (GUNDERSON e HOLLING 2002), "[...] a resiliência de um sistema precisa ser considerada em termos dos atributos que governam a dinâmica desse sistema" (WALKER, HOLLING, CARPENTER et al., 2004, p. 1). No que diz respeito aos sistemas socioecológicos (SESs), há três atributos: resiliência, adaptabilidade e transformabilidade.

Resiliência é a capacidade de um sistema de absorver perturbações e se reorganizar enquanto enfrenta mudanças de forma que ainda mantenha, essencialmente, os mesmos função, estrutura, identidade e feedbacks. Adaptabilidade é a capacidade dos atores em um sistema de influenciar a resiliência (em um SES, de essencialmente gerenciá-lo)...Transformabilidade é a capacidade de criar um sistema fundamentalmente novo quando estruturas ecológicas, econômicas ou sociais tornam o sistema existente insustentável (WALKER, HOLLING, CARPENTER et al., 2004, p.1).

Note-se que a resiliência e a adaptabilidade encontram-se dentro da dinâmica de um dado sistema e a transformabilidade dentro da capacidade de alterar a natureza do referido sistema (WALKER, HOLLING, CARPENTER et al., 2004).

Com base nessa perspectiva de sistemas complexos, Burnard e Bhamra (2011) apresentam quatro proposições epistemológicas para sustentar um modelo de resposta organizacional resiliente por eles proposto e definem que:

Resiliência é a propriedade emergente de sistemas organizacionais que se relaciona às qualidades e capacidades inerentes e adaptativas que viabilizam a capacidade adaptativa geral de uma organização durante períodos turbulentos. Assim, os mecanismos de resiliência organizacional visam melhorar a percepção situacional da organização, reduzir as vulnerabilidades a ambientes de risco sistêmico e restabelecer a eficácia após eventos de ruptura (BURNARD e BHAMRA, 2011, p. 5587).

No que diz respeito a grandes rupturas devido a mudanças radicais no ambiente, as respostas organizacionais vêm sendo primariamente caracterizadas segundo regras de rigidez, ou seja, somente por meio de uma resposta rígida (controles rígidos, centralização da decisão, canais verticais e tradicionais de comunicação e execução das tarefas, etc.) uma organização consegue efetivamente mitigar rupturas maiores ou ameaças que levem a um ajuste. Diante do esgotamento do controle centralizado e da execução do trabalho por meio de canais tradicionais, as oportunidades de desenvolvimento tornam-se restritas. Uma resposta flexível pode permitir um ajuste positivo à turbulência, por meio da ativação das capacidades do sistema organizacional de coping, recuperação, adaptação e de se mover diante dos eventos de ruptura (WEICK e SUTCLIFFE, 2001; SUTCLIFFE e VOGUS, 2003).

Independentemente da forma e do tamanho da ameaça ou da ruptura, o fato é que organizações enfrentam adversidades diariamente, e a forma pela qual uma organização confronta e supera tais adversidades pode torná-la inflexível e frágil, conforme ela responda de forma rígida, ou flexível e adaptável, conforme ela responda pela ativação de um repertório de competências e rotinas que restaurem a sua eficácia e promovam crescimento (SUTCLIFFE e VOGUS 2003).

Lengnick-Hall, Beck e Lengnick-Hall (2011) conceituam, respectivamente, flexibilidade como a habilidade de mudar em um prazo relativamente curto e a um baixo custo, agilidade como a habilidade de desenvolver e aplicar rapidamente manobras competitivas, e adaptabilidade como a habilidade de restabelecer o fit com o ambiente externo, ensinam que entre o 
constructo da resiliência organizacional e estes três atributos, embora existam pontos de convergência, há importantes distinções a serem feitas, e que "[...] conquanto características como flexibilidade, adaptação, improvisação e agilidade possam contribuir para a capacidade de resiliência de uma organização, nenhuma delas isoladamente é suficiente para alcançar a resiliência" (LENGNICK-HALL, BECK e LENGNICK-HALL 2011, p. 244).

Tomada de forma conjunta, a literatura sobre resiliência organizacional sugere que organizações resilientes apresentam uma série de características importantes, tais como (DENHARDT e DENHARDT, 2010, p. 338): redundância ou excesso de capacidade, robustez, flexibilidade, credibilidade (reliability) e confiança e respeito.

Para Denhardt e Denhardt (2010), líderes e gestores em todas as organizações deveriam buscar o desenvolvimento da resiliência a qualquer tempo, não somente no enfrentamento de crises ou desastres internos ou externos. Afinal, no desempenho dessas funções, eles são os responsáveis pela condução da organização, pela implementação de mudanças e por sua necessária sustentação pelo aparato simbólico (MOTTA, 2007), considerando a cultura organizacional como um recurso intangível e como o elemento responsável por mediar a relação entre o modelo de gestão formalmente concebido e os recursos tangíveis, o que inclui os elementos do sistema organizacional (pessoas e processos) (AKTOUF, 2004).

\section{RESILIÊNCIA ORGANIZACIONAL: PROPOSIÇÃO DE UM MODELO DE ANÁLISE}

As concepções de resiliência como uma capacidade relativa e circunstancial ensejam tentativas de responder a pergunta de como as qualidades de resiliência são adquiridas, o que tem colocado a resiliência sob as lentes de uma perspectiva de processo.

A resiliência organizacional engloba tanto a relativa a indivíduos quanto a de um sistema, que conta com a resposta adaptativa dos indivíduos e da organização diante de descontinuidades sistemáticas e rupturas de maior vulto (DENHARDT e DENHARDT, 2010). A resiliência de um sistema é uma abordagem conceitual utilizada na ecologia, que se refere à capacidade de os sistemas naturais se recuperarem de pressões ambientais, de tal forma que a sustentabilidade do sistema não seja comprometida (HORNE 1997; WALKER, HOLLING, CARPENTER et al., 2004), sendo certo que, no que diz respeito à organização, a concepção de sistema é a de um sistema social que é construído, ou seja, organizações são socialmente construídas, com base em elementos tais como relações de poder, recursos, autoridade, regras e procedimentos (DENHARDT e DENHARDT, 2010, p.335). A habilidade de construir significado permite que organizações (de pessoas) modifiquem a configuração (do sistema) e "[...] virem de um tipo de organização para outro tipo e de volta ao tipo inicial" (WESTLEY, CARPENTER, BROCK et al., 2002, p. 104). Assim, uma vez que organizações são constituídas de atores humanos, seus comportamentos, individuais e coletivos contribuem ou impedem a resiliência organizacional.

Dessa forma, tanto as capacidades individuais usadas coletivamente quanto aspectos relacionados a capacidades do sistema estão abrigados no conceito de resiliência organizacional.

Recuperação, adaptação positiva a adversidade e sustentabilidade do equilíbrio (físico e emocional e sistêmico) são elementos do conceito de resiliência, conforme Reich, Zautra e Hall (2010), Youssef e Luthans (2007), Masten e Wright (2010), Weick e Sutcliffe (2001) Sutcliffe e Vogus (2003), Hamel e Valikangas (2003) e Denhardt e Denhardt (2010).

Quando se questiona sobre como um indivíduo adquire as características ou qualidades que viabilizam tanto o processo como o resultado (resiliente) (LUTHAR, CICCHETTI e BECKER, 2000), esses elementos permitem que a resiliência seja estudada simultaneamente sob a perspectiva de um processo dinâmico e um estado final (ou resultado) - de adaptação positiva e superação - observados após a exposição à adversidade (WALLER, 2001).

A definição de Waller (2001) expressa de forma significativa essa abordagem. Ela define resiliência humana como "[...] um produto - multideterminado e sempre mutável - de forças que interagem em determinado contexto ecossistêmico" (WALLER, 2001, p. 290).

Assim, a resiliência como um ciclo de causa - exposição a adversidade, e resultado - adaptação positiva - pode ser alicerçada em um conceito abrangente e multifacetado. 
Como uma capacidade processual, dinâmica e ecossistêmica, a resiliência é acionada em resposta a eventos cuja qualificação como adversidade é dependente de uma apreciação que varia de indivíduo para indivíduo. A forma como tal capacidade manifesta-se determinará um resultado de adaptação positiva, que pode ser saudável ou não.

O ciclo que vai do acionamento da capacidade, partir da exposição à adversidade, até a geração do resultado inclui: propriedades cognitivas e comportamentais, traços de personalidade, conhecimento sistemático e não sistemático e interações sociais/ ambientais e interpessoais. O processo de se adaptar, aprender e mudar, e se tornar mais resiliente, pressupõe a recuperação do equilíbrio no enfrentamento da adversidade e do (eventual) estresse causado por ela.

Assim, propõe-se o seguinte conceito de "resiliência organizacional": capacidade processual, dinâmica e ecossistêmica, ativada por pessoas (resiliência individual) e processos (resiliência sistêmica) em face de adversidades, para a geração de uma resposta que permita a recuperação do equilíbrio e a realização de uma adaptação saudável, mediante o acionamento de elementos ou ativos nos planos subjetivo ou interno e objetivo ou externo. que poderão ser reforçados ou renovados durante o processo, garantindo a sustentabilidade do resultado resiliente e/ou a expansão da capacidade de resiliência.

Diante deste conceito e considerando-se os elementos da resiliência individual e da sistêmica, assim como aspectos contextuais que permeiam as relações que se passam nos níveis micro e macro de análise, propôs-se um modelo de análise de "resiliência organizacional" conforme Figura 2.

Figura 2

Modelo Multinível de Resiliência Organizacional

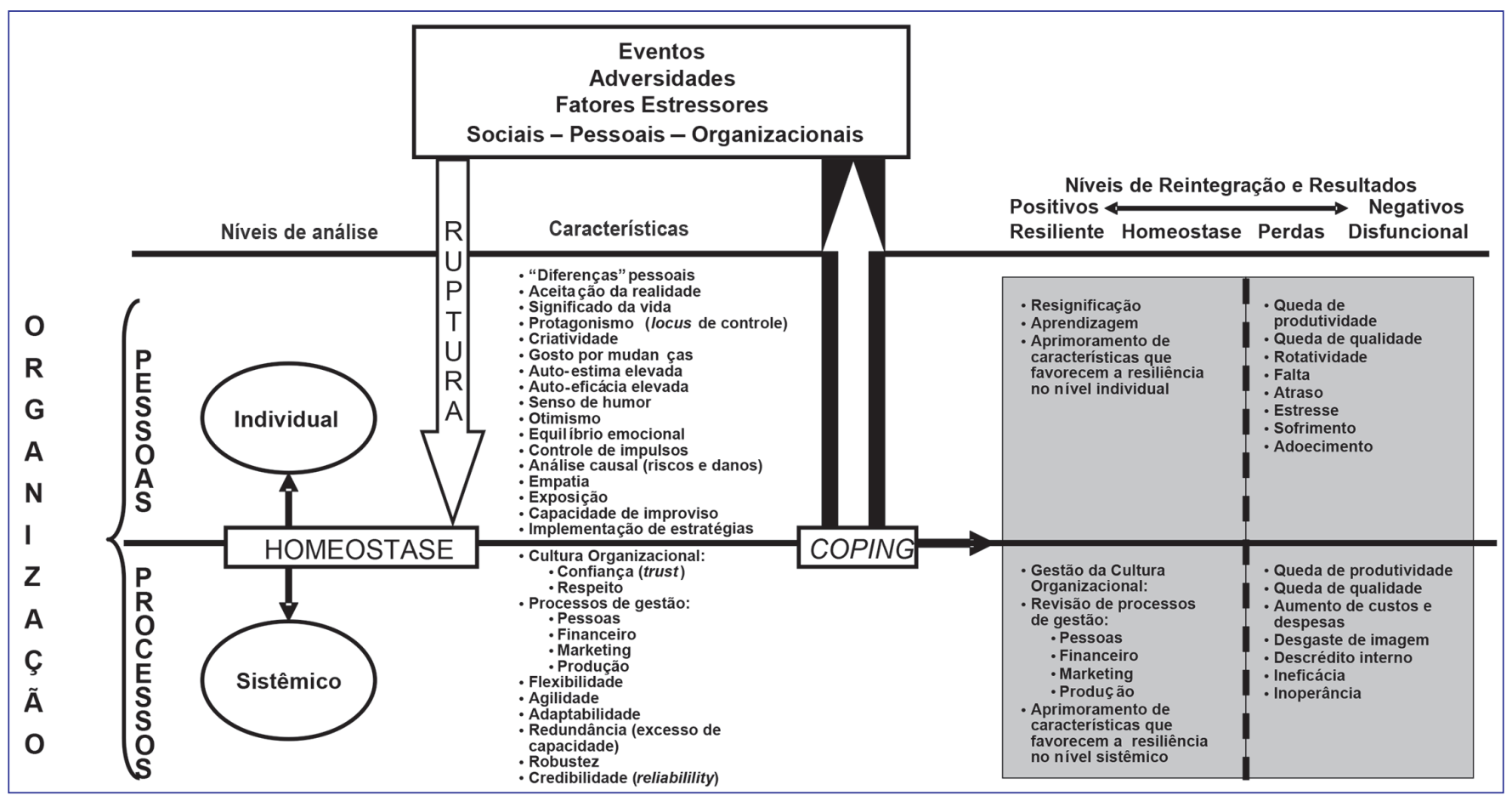

Fonte: Levantamento bibliográfico.

Esse modelo permite observar e analisar a resiliência organizacional como fruto da integração de dois componentes, pessoas e processos, o que sinaliza dois níveis de análise - individual e sistêmico respectivamente -, que podem ser observados tanto na sua totalidade, como nas partes, ou mesmo em características específicas, como as identificadas na literatura acessada, assim como seus níveis de reintegração e resultados - positivos e negativos. Tais possibilidades conferem robustez ao modelo proposto e potencialidades em termos de pesquisas futuras, visando tanto aos interesses acadêmicos como de outras esferas da sociedade (organizações, profissionais etc.), conforme se sugere adiante. 


\section{PERSPECTIVAS DE PESQUISAS E CONSIDERAÇÕES FINAIS}

Do ponto de vista metodológico, visando à ampliação e ao aprofundamento no estudo do tema e aos possíveis recortes em termos de foco e ênfase, sugere-se a realização de pesquisas descritivo-comparativas, tanto no nível individual como sistêmico da resiliência organizacional, de modo a se aprofundar nos elementos apresentados no modelo, visando ampliar sua robustez. Por um lado, abarcar organizações de um mesmo setor de atividade pode promover identificação, compreensão e comparação de aspectos envolvidos nos níveis micro, meso e macro delineados no modelo proposto. Por outro lado, a riqueza de estudos mais amplos, com organizações de diversos setores produtivos, o que inclui o público e o terceiro setor, também podem promover tal amplitude e o desnudamento de facetas e peculiaridades que tenham relação direta com os elementos e os resultados da resiliência, nos referidos níveis.

Devido ao estágio de desenvolvimento das pesquisas sobre o constructo no Brasil, sugerem-se pesquisas com abordagens qualitativas, uma vez que buscam compreensão de significados e relações subjacentes a situações - neste caso, eventos, adversidades e pressões - que podem ser descritos pelos trabalhadores abordados, assim como observados em dados levantados em documentos, protocolos etc. nas organizações. (COZBY, 2003; TRIVIÑOS, 1987). Com o desenvolvimento de pesquisas nesses moldes, abrem-se perspectivas para validação de escalas que permitam coletas de dados diferenciadas, ou seja, uma abordagem quantitativa, para daí ampliar a capacidade de generalização dos achados, visto que tal abordagem usualmente favorece mensuração e comparação (COLLINS e HUSSEY, 2005). Nesse sentido, triangulações metodológicas podem ser extremamente úteis no estudo da resiliência, tendo em vista os níveis de análise observados e a mescla entre amplitude (abordagem quantitativa) e profundidade (abordagem qualitativa) que a combinação de métodos complementares pode promover, afinal, como destaca

Demo (2002), [...] o objetivo da pesquisa qualitativa é desnudar os aspectos menos formais dos fenômenos em questão, sem desconsiderar, no entanto, sua faceta quantitativa, já que tal dicotomia não é, segundo ele, real. Para Demo (2002), todo fenômeno histórico quantitativo que envolve o ser humano contém uma dimensão qualitativa; o qualitativo, por sua vez, é histórico e guarda, dessa forma, um contexto material, temporal e espacial. $O$ autor conclui que dicotomização absoluta entre tais faces é apenas uma fiç̧ão conceitual. (PAIVA e MELO, 2008, p. 358).

Considerando-se tais abordagens, passa-se aos instrumentos de coleta de dados. Em pesquisas qualitativas, os mais comuns são o levantamento documental, entrevistas (com roteiros diversos, ou seja, não estruturados, semiestruturados ou estruturados) e observação direta, conforme tipificação de Bruyne, Herman e Schoutheete (1977). Estudos no país têm mostrado que técnicas complementares de pesquisa também podem ser úteis, como as técnicas projetivas,_no sentido de levantar dados que usualmente não são explicitados em entrevistas e, muito menos, em questionários (MELO, PAIVA, MAGESTE et al., 2007).

No caso do tema em questão, resiliência organizacional, o levantamento documental pode se dar em dados dos trabalhadores, disponibilizados pela área de recursos humanos ou outras instâncias com as quais tal área dialoga (associações ou conselhos profissionais, sindicatos, Ministério do Trabalho etc.), e em dados da organização, como projetos, planejamento estratégico, apurações de resultados, dados contábeis etc. As entrevistas, por sua vez, podem ser realizadas com trabalhadores dos mais diversos níveis hierárquicos, tendo em vista as peculiaridades da função gerencial, além de considerar outras diferenças que têm sido alvo de preocupação dentro das organizações, como diferenças de gênero, orientação sexual, faixa etária, cor de pele etc., já que espelham debates mais amplos na sociedade brasileira atualmente.

As razões e formas de se entrar, e sair, do campo de pesquisa também são aspectos importantes a serem considerados no estudo da resiliência, tendo em vista a delicadeza aí envolvida: são pessoas, vidas que estão no alvo da compreensão e isso não pode ser ignorado. Formalmente, critérios de saturação de dados (métodos qualitativos) e de amostragem (métodos quantitativos) são considerados argumentos "mínimos" para se trabalhar com coerência e consistência na pesquisa acadêmica. Além disso, as orientações e exigências prescritas na Resolução 510 do Conselho Nacional de Saúde (CONSELHO NACIONAL DE SAÚDE, 2016), que trata de pesquisas com seres humanos no país e que norteia a atuação dos comitês de ética em pesquisa espalhados pelo país, vêm sendo cada dia mais observadas, mesmo considerando riscos mínimos ou inexistentes, de qualquer natureza, de abordar tais objetos na pesquisa científica, e ainda que no campo das ciências sociais aplicadas, como é o caso da Administração. 
O tratamento dos dados, por sua vez, é realizado conforme a sua natureza. Assim sendo, dados oriundos de fontes secundárias, no caso do levantamento documental, usualmente são submetidos à análise documental; quanto aos dados primários, os advindos de métodos qualitativos são, geralmente, tratados por meio de análise de conteúdo e/ou de discurso; e os coletados por meio de caráter quantitativo são submetidos a tratamento estatístico, cujo nível de refinamento pode variar conforme os objetivos definidos no escopo da pesquisa (COLLINS e HUSSEY, 2005).

Quanto a perspectivas e conexões temáticas, o constructo resiliência organizacional pode ser trabalhado nos níveis apresentados no modelo, de modo integrado ou, dependendo do recorte da pesquisa, em partes que o compõem.

Além disso, algumas possibilidades podem ser demarcadas, haja vista as iniciativas de pesquisa sobre o tema no país, como é o caso de:

a) no nível individual, seria interessante pesquisar elementos da resiliência em profissionais:

- da mesma organização, em organizações semelhantes e em organizações de setores diversos (privada, pública, mista, sem fins lucrativos, cooperativas, associações etc.), para fins imediatos de comparação;

- da mesma organização, porém em setores diferentes; níveis hierárquicos diferentes, chamando-se atenção para as questões relativas ao exercício da função gerencial;

- com vínculos empregatícios diferentes, tendo em vista o avanço dos processos de terceirização, inclusive no âmbito legal, assim como do trabalho autônomo e informal;

- em diversas organizações, porém estereotipados como "diferentes", considerando-se as diferenças mencionadas anteriormente, como gênero, orientação sexual, faixa etária, cor de pele etc., com vistas a possíveis melhorias nas políticas e práticas de gestão de pessoas;

- $\quad$ submetidos às inegáveis relações de poder que permeiam todo e qualquer tipo de organização, suas formas de coping, inclusive as consideradas não satisfatórias, que podem findar em adoecimento, ações judiciais movidas em função de assédio moral;

- $\quad$ em profissões diferenciadas, o que se reflete na sua valorização no mercado, tanto em termos simbólicos como remuneratórios;

- e suas relações com configurações identitárias nos diversos níveis passíveis de observação (MACHADO, 2003);

b) no nível sistêmico: processos relativos à gestão de pessoas, incluindo-se as políticas e práticas, degraus entre elas e perspectivas de melhoria, assim como estilos de gerência e de liderança de pessoas; gestão financeira; gestão de marketing; gestão de produção;

c) no nível organizacional: relacionando a visão macro da resiliência a práticas de sustentabilidade, de inovação, suas competências essenciais, capacidades dinâmicas, modelos de gestão, aprendizagem organizacional (VASCONCELOS, CYRINO, D’ OLIVEIRA et al., 2015), de responsabilidade social, gestão de imagem etc.

A finalidade da proposição dessa agenda de pesquisa foi colaborar no seguinte sentido: primeiro, acadêmico e conceitual, visando sustentar uma delimitação, ainda que parcial e temporária, para o constructo e contribuir para seu debate; segundo, pragmático, objetivando subsidiar trabalhadores e organizações de elementos que possam ser úteis nos processos direta e indiretamente envolvidos na resiliência organizacional, quer no nível individual, quer no sistêmico, como apresentado no modelo proposto.

Longe da presunção de encerrar qualquer discussão a tal respeito, a intenção desse ensaio foi contribuir para o debate de um construto que engloba processos altamente complexos, que envolvem níveis diferenciados de análise e que estão submetidos a lógicas nem sempre claras e precisas, tanto para o indivíduo como para a organização, de modo amplo aqui considerados. 


\section{REFERÊNCIAS}

AKTOUF, O. Pós-globalização, administração e racionalidade econômica: a síndrome do avestruz - reflexões sobre a miopia do pensamento econômico e administrativo contemporâneo. São Paulo: Atlas, 2004.

ANDRADE, C. R.; GUIMARÃES, L. V. M.; ASSIS, L. B. Análise Crítica das Pesquisas em Estresse Ocupacional da Anpad: afinal, cadê o sujeito? In: EnANPAD, 34., 2010, Rio de Janeiro. Anais... Rio de Janeiro, ANPAD, 2010.

ANTONIAZZI, A. S.; BANDEIRA, D. R.; DELL'AGLIO, D. D. O conceito de coping: uma revisão teórica. Estudos de Psicologia, v. 3, n. 2, p. 273-294, 1998.

BEER, F. P.; JOHNSTON JR., E. R. Resistência dos materiais. São Paulo: McGraw-Hill, 1989.

BEEGHLY, M.; CICCHETTI, D. Child maltreatment, attachment, and the self system: emergence of an internal state lexicon in toddlers at high social risk. Development and Psychopathology, v. 6, n. 1, p. 5-30, 1994.

BENSON, P. L. All kids are our kids. Minneapolis: Search Institute, 1997.

BLOCK, J. H.; BLOCK, J. The role of ego-control and ego-resiliency in the organization of behavior. In: COLLINS, W. A. (Ed.). Minnesota Symposia on Child Psychology. v. 13. Hillsdale, NJ: Erlbaum, 1980. p. 39-101.

BLOCK, J.; KREMEN, A. M. IQ and ego-resiliency: conceptual and empirical connections and separateness. Journal of Personality and Social Psychology, v. 70, n. 2, p. 349-361, 1996.

BONNANO, G. A. Loss, trauma, and human resilience. Have we underestimated the human capacity to thrive alter extremely aversive events? American Psychologist, v. 59, n. 1, p. 20-28, 2004.

BRANDÃO, J.; MAHFOUD, M.; GIANORDOLI-NASCIMENTO, I. A construção do conceito de resiliência em psicologia: discutindo as origens. Paidéia, v. 21, n. 49, p. 263-271, 2011.

BRUYNE, P.; HERMAN, J.; SCHOUTHEETE, M. Dinâmica da Pesquisa em Ciências Sociais. Rio de Janeiro: Francisco Alves, 1977.

BURNARD, K.; BHAMRA, R. Organisational resilience: development of a conceptual framework for organisational responses. International Journal of Production Research, v. 49, n. 18, p. 5581-5599, 2011.

CARMELLO, E. Resiliência: a transformação como ferramenta para construir empresas de

valor. São Paulo: Editora Gente, 2008.

CARVER, C. S. Resilience and thriving: issues, models, and linkages. Journal of social issues, v. 54, n. 2, p. 245-266, 1998.

CICCHETTI, D.; ROGOSCH, F. A. The role of self-organization in the promotion of resilience in maltreated children. Development and psychopathology, v. 9, n. 4, p. 797-815, 1997.

CHARNEY, D. S. Psychobiological mechanisms of resilience and vulnerability - implications for successful adaptation to extreme stress. FOCUS: The Journal of Lifelong Learning in Psychiatry, v. 2, n. 3, p. 368-391, 2004.

COLLINS, J.; HUSSEY, R. Pesquisa em Administração. Porto Alegre: Bookman, 2005.
CONNER, D. R. Gerenciando na velocidade da mudança: como gerentes resilientes são bem sucedidos e prosperam onde outros fracassam. Rio de Janeiro: Infobook, 1995.

CONSELHO NACIONAL DE SAÚDE-CNS. Resolução 510, de 07/04/2016. Trata das pesquisas com seres humanos. DOU, n. 98 , s. 1, p. 44-46, 24/05/2016.

COUTU, D. L. How resilience works. Harvard business review, v. 80, n. 5, p. 46-56, 2002.

COZBY, P. C. Métodos de Pesquisa em Ciências do Comportamento. São Paulo: Atlas, 2003.

DAVEL, E.; MELO, M. C. O. L. Singularidades e transformações no trabalho dos gerentes. In: DAVEL, E.; MELO, M. C. O. L. (Org.). Gerência em Ação. Rio de Janeiro: FGV, 2005. 29-65 p.

DENHARDT, J.; DENHARDT, R. Building organizational resilience and adaptive management. In: REICH, J. W.; ZAUTRA, A. J.; HALL, J. $S$. Handbook of adult resilience. New York, London: The Guilford Press, 2010. 333-349 p.

DESLANDES, S. F.; JUNQUEIRA, M. F. P. Resiliência e maus tratos à criança. Cadernos de Saúde Pública, v. 19, n. 1, p. 227-235, 2003.

FLACH, F. Psychobiologic resilience, psychotherapy and the creative process. Comprehensive Psychiatry, v. 21, n. 6, p. 510-519, 1980.

FLACH, F. Resiliência: a arte de ser flexível. São Paulo: Saraiva, 1991.

GALENDE, E. Subjetividad y resiliencia: del azar y la complejidad. In: MELILLO, A.; OJEDA, E. N. S.; RODRIGUEZ, D. (Org). Resiliencia y subjetividad. Buenos Aires: Paidós, 2004. 23-61 p.

GARCIA, I. Vulnerabilidade e resiliência. Adolescência Latinoamericana, v. 2, n. 3, p. 128-30, 2001.

GARMEZY, N.; MASTEN, A. S.; TELLEGEN, A. The study of stress and competence in children: a building block for developmental psychopathology. Child Development, v. 55, n. 1, p. 97-111, 1984.

GARMEZY, N. The study of competence in children at risk for severe psychopathology. In: ANTHONY, E. J.; KOUPERNIK, C. (Eds.). The child and his family. Children at psychiatric risk. New York: Wiley, 1974. v. 3. 77-97 p.

GROTBERG, E. H. Tapping your inner strength: how to find the resilience to deal with anything. Oakland, CA: New Harbinger, 1999.

GROTBERG, E. H. Introdução: novas tendências em resiliência. In: MELILLO, A.; OJEDA, E. N. S. (Org.). Resiliência: descobrindo as próprias fortalezas. Porto Alegre: Artes Médicas, 2005. 15-22 p.

GROTBERG, E. H. La resiliencia en el mundo de hoy. Cómo superar las adversidades. Barcelona: Gedisa, 2006.

GUNDERSON, L. H.; HOLLING, C. S. Preface. In: GUNDERSON, L. H.; HOLLING, C. S. (Eds.). Panarchy: understanding transformations in human and natural systems. Washington, DC: Island Press, 2002. $x x i-x x i v p$.

GUZZO, R. S. L.; TROMBETA, L. H. A. P. Enfrentando o cotidiano adverso: estudo sobre resiliência em adolescentes. Campinas: Alínea, 2002.

HAMEL, G.; VALIKANGAS, L. The quest for resilience. Harvard Business Review, v. 81, n. 9, p. 52-65, 2003. 
HILL, L. A. Novos gerentes: assumindo uma nova identidade. São Paulo: Makron Books, 1993.

HORNE, J. F. The coming age of organizational resilience. Business Forum, v. 22, n. 2/3/4, p. 24-28, 1997.

HORNE, J. F.; ORR, J. E. Assessing behaviors that create resilient organizations. Employment Relations Today, v. 24, n. 4, p. 29-39, 1997.

INFANTE, F. A resiliência como processo: uma revisão da literatura recente. In: MELILLO, A.; OJEDA, E. N. S. (Org.). Resiliência: descobrindo as próprias fortalezas. Porto Alegre: Artes Médicas, 2005. 23-38 p.

JACELON, C. The trait and process of resilience. Journal of Advanced Nursing, v. 25, n. 1, p. 123-129, 1997.

JACKSON, D.; FIRTKO, A.; EDENBOROUGH, M. Personal resilience as a strategy for surviving and thriving in the face of workplace adversity: a literature review. Journal of advanced nursing, v. 60, n. 1 , p. 1-9, 2007

KENT, M.; DAVIS, M. C. The emergence of capacity-building programs and models of resilience. In: REICH, J. W.; ZAUTRA, A. J.; HALL, J. S. Handbook of adult resilience. New York, London: The Guilford Press, 2010. p. 427-449.

LAZARUS, R. S.; FOLKMAN, S. Stress, appraisal, and coping. New York: Springer, 1984.

LENGNICK-HALL, C. A.; BECK, T. E.; LENGNICK-HALL, M. L. Developing a capacity for organizational resilience through strategic human resource management. Human Resource Management Review, v. 21, n. 3, p. 243-255, 2011.

LIMONGI-FRANÇA, A. C.; RODRIGUES, A. L. Stress e trabalho: uma abordagem psicossomática. São Paulo: Atlas, 2005.

LISSACK, M. R.; LETICHE, H. Complexity, emergence, resilience, and coherence: gaining perspective on organizations and their study. Emergence: Complexity and Organization, v. 4, n. 3, p. 72-94, 2002.

LUTHANS, F. The need for and meaning of positive organizational behavior. Journal of Human Behavior, v. 23, n. 6, p. 695-706, 2002.

LUTHAR, S.; CICCHETTI, D. The construct of resilience: implications for interventions and social policies. Development and Psychopathology, v. 12, n. 4, p. 857-885, 2000.

LUTHAR, S.; CICCHETTI, D.; BECKER, B. The construct of resilience: a critical evaluation and guidelines for future work. Child Development, v. 71, n. 3, p. 543-562, 2000.

MACHADO, H. V. A identidade e o contexto organizacional: perspectivas de análise. Revista de Administração Contemporânea - RAC, v. 7, n. especial, p. 51-73, 2003.

MALLACK, L. Putting organizational resilience to work. Industrial Management, v. 40, n. 6, p. 8-13, 1998.

MARTINEAU, S. Rewriting resilience: a critical discourse analysis of childhood resilience and the politics of teaching resilience to "kids at risk". 1999. Tese (Doutorado) - The University of British Columbia, 1999.

MASTEN, A. S. Ordinary magic: resilience processes in development. American Psychologist, v. 56, n. 3, p. 227-238, 2001.

MASTEN, A. S.; WRIGHT, M. Resilience over the lifespan: developmental perspectives on resistance, recovery, and transformation. In: REICH, J. W.; ZAUTRA, A. J.; HALL, J. S. Handbook of adult resilience. New York, London: The Guilford Press, 2010. 213-237 p.
MELILLO, A. Sobre la necesidad de especificar un nuevo pilar de la resiliencia. In: MELILLO, A.; OJEDA, E. N. S.; RODRIGUEZ, D. (Org.). Resiliencia y subjetividad. Buenos Aires: Paidós, 2004. 77-90 p.

MELO, M. C. O. L. et al. M. Em busca de técnicas complementares em pesquisa qualitativa no campo da administração. In: EnEPQ, 1, 2007, Recife. Anais... Recife, ANPAD, 2007.

MOTTA, P. R. Gestão Contemporânea: a ciência e a arte de ser dirigente. Rio de Janeiro: Record, 2007.

O'DOUGHERTY-WRIGHT, M.; MASTER, A. S.; HUBBARD, J. J. Longterm effects of massive trauma: Developmental and psychobiological perspectives. In: CICCHETTI, D.; TOTH, S. L. (Eds.). Rochester Symposium on Developmental Psychopathology: Developmental perspectives on trauma. v. 8. Rochester, NY: University of Rochester Press, 1997. 181-225 p.

PAIVA, K. C. M. Das "competências profissionais" às "competências laborais": modelo de análise e agendas de pesquisa. Tourism \& Management Studies, v. 2, n. especial, p. 502-510, 2013.

PAIVA, K. C. M.; GOMES, M. A. N.; HELAL, D. H. Estresse ocupacional e síndrome de burnout: proposição de um modelo integrativo e perspectivas de pesquisa junto a docentes do ensino superior. Gestão \& Planejamento, v. 16, n. 3, p. 285-309, 2015.

PAIVA, K. C. M.; MELO, M. C. O. L. Competências, gestão de competências e profissões: perspectivas de pesquisas. Revista de Administração Contemporânea - RAC, v. 12, n. 2, p. 339-368, 2008.

PAIVA, K. C. M. et al. Estresse Ocupacional e Burnout de jovens trabalhadores. In: EnANPAD, 37, 2013, Rio de Janeiro. Anais... Rio de Janeiro, ANPAD, 2013.

PIAGET, J. Part I: Cognitive Development in Children: Piaget Development and Learning. Journal of Research in Science Teaching, v. 2, n. 3, p. 176-186, 1964.

PIAGET, J. Psicogênese dos conhecimentos e seu significado epistemológico. In: PIATELLI-PALMARINI, M. (Org.). Teorias da linguagem: teorias da aprendizagem; o debate entre Jean Piaget e Noam Chomsky. São Paulo: Cultrix, 1983. 39-49 p.

PIAGET, J. O nascimento da inteligência na criança. Rio de Janeiro: Guanabara, 1987

POLK, L. Toward a middle-range theory of resilience. Advanced Nursing Science, v. 19, n. 3, p. 1-13, 1997.

REED, M. Sociologia da Gestão. Oeiras: Celta, 1997.

REICH, J. W.; ZAUTRA, A. J.; HALL, J. S. Preface. In: REICH, J. W.; ZAUTRA, A. J.; HALL, J. S. Handbook of adult resilience. New York, London: The Guilford Press, 2010. xi-xv p.

REIVICH, K.; SHATTÈ, A. The resilience factor: 7 essential skills for overcoming life's inevitable obstacles. New York: Broadway BooksRandom House, 2002.

RICHARDSON, G. E. et al. The resiliency model. Health Education, v. 21, n. 6, p. 33-39, 1990.

RICHARDSON, G. R. The metatheory of resilience and resiliency. Journal of Clinical Psychology, v. 58, n. 3, p. 307-321, 2002.

RODRIGUES, S. B.; CHILD, J.; LUZ, T. R. Aprendizagem contestada em ambiente de mudança radical. Revista de Administração de Empresas - RAE, v. 44, n. 1, p. 27-43, 2004.

ROTTER, J. B. Generalised expectations for internal versus external control of reinforcement. Psychology Monograph, v. 80, n. 1, p. 1-28, 1966. 
RUTTER, M. Resilience in the face of adversity: protective factors and resistance to psychiatric disorder. British Journal of Psychiatry, v. 147 , n. 6, p. 598-611, 1985.

RUTTER, M. Resilience concepts and findings: implications for family therapy. Journal of Family Therapy, v. 21, n. 2, p. 119-144, 1999.

SKODOL, A. E. A resilient personality. In: REICH, J. W.; ZAUTRA, A. J.; HALL, J. S. Handbook of adult resilience. New York, London: The Guilford Press, 2010. 112-125 p.

SUTCLIFFE, K. M.; VOGUS, T. J. Organizing for resilience. In: CAMERON, K. S.; DUTTON, J. E.; QUINN, R. E. (Eds.), Positive organizational scholarship: Foundations of a new discipline. San Francisco: BerrettKoehler, 2003. 94-110 p.

TABOADA, N. G.; LEGAL, E. J.; MACHADO, N. Resiliência: em busca de um conceito. Revista brasileira de crescimento e desenvolvimento humano, v. 16, n. 3, p. 104-113, 2006.

TAVARES, J. A resiliência na sociedade emergente. In: TAVARES, J. (Org.). Resiliência e educação. São Paulo: Cortez, 2001. 43-76 p.

TRAVERS, C. J., COOPER, C. L. Teachers under preassure. London: Routledge, 1996.

TRIVIÑOS, A. N. S. Introdução à Pesquisa em Ciências Sociais. São Paulo: Atlas, 1987.

TUGADE, M; FREDRICKSON, B. Resilient individuals use emotions to bounce back from negative emotional experiences. Journal of Personality and Social Psychology, v. 86, n. 2, p. 320-333, 2004.

TUSAIE K.; DYER J. Resilience: a historical review of the construct. Holistic Nursing Practice, v. 18, n. 1, p. 3-10, 2004.

VASCONCELOS, I. F. F. et al. Resiliência organizacional e inovação sustentável: um estudo sobre o modelo de gestão de pessoas de uma empresa brasileira de energia. Cad. EBAPE.BR, v. 13, n. 4, p. 910-929, 2015.
WALKER, B. et al. Resilience, adaptability and transformability in social-ecological systems. Ecology and Society, v. 9, n. 2, art. 5, 2004.

WALLER, M. A. Resilience in ecosystemic context: evolution of the concept. American Journal of Orthopsychiatry, v. 71, n. 3, p. 290297, 2001.

WEICK, K. E.; SUTCLIFFE, K. M. Managing the unexpected: resilient performance in an age of uncertainty. San Francisco, CA: JosseyBass, 2001.

WERNER, E.E.; SMITH R.S. Overcoming the odds: high-risk children form birth to adulthood.Ithaca: CornellUniversity Press, 1992.

WESTLEY, F. et al. Why systems of people and nature are not just social systems. In: GUNDERSON, L. H.; HOLLING, C. S. (Eds.). Panarchy: understanding transformations in human and natural systems. Washington, DC: Island Press, 2002. 103-119 p.

YOUSSEF, C.; LUTHANS, F. Positive organizational behavior in the workplace: the impact of hope, optimism, and resilience. Journal of Management, v. 33, n. 5, p. 774-800, 2007.

YUNES, M. A. Psicologia positiva e resiliência: o foco no indivíduo e na família. Psicologia em estudo, v. 8, n. 1, p. 80-95, 2003.

YUNES M. A.; SZYMANSKI, H. Resiliência: noção, conceitos afins e considerações críticas. In: TAVARES, J. (Org.). Resiliência e educação. São Paulo: Cortez, 2001. 13-42 p.

YUNES, M. A.; SZYMANSKI, H. Entrevista reflexiva \& grounded-theory: estratégias metodológicas para compreensão da resiliência em famílias. Revista Interamericana de Psicologia, v. 39, n. 3, p. 431-438, 2005.

ZAUTRA, A. J.; HALL, J. S.; MURRAY, K. E. Resilience: a new definition of health for people and communities. In: REICH, J. W.; ZAUTRA, A. J.; HALL, J. S. Handbook of adult resilience. New York, London: The Guilford Press, 2010. 3-29 p.

ZIMMERMAN, M. A.; ARUNKUMAR, R. Resiliency research: Implications for schools and policy. Social Policy Report, v. 8, n. 4, p. 1-18, 1994.

Hélio Arthur Reis Irigaray

Doutor em Administração de Empresas pela FGV EAESP, Mestre em Administração de Empresas pela PUC-Rio e Bacharel em Economia pela University of Nothern lowa; Professor adjunto da FGV EBAPE, Coordenador do Global MBA, parceria com a Manchester Business School; Professor adjunto da Georgetown University e ESADE, no programa de mestrado CIM; Líder de tema Diversidade da Força de Trabalho, na linha de Gestão de Pessoas e Relações de Trabalho (ANPAD). E-mail: helio.irigaray@fgv.br

Kely Cesar Martins de Paiva

Doutora, Mestre e Bacharel em Administração pela UFMG; Professora adjunta da UFMG e Centro de Pós-Graduação e Pesquisas em Administração - CEPEAD/UFMG; Líder do tema Gestão de Pessoas e Elementos do Comportamento Organizacional, na linha de Gestão de Pessoas e Relações de

Trabalho (ANPAD). E-mail: kelypaiva@face.ufmg.br

Cristina Chaves Goldschmidt

Mestre em Administração pela FGV EBAPE; Bacharel em Direito pela Universidade Cândido Mendes e em Letras pela UERJ; Professora autora do Pós ADM/FGV e dos MBAs/FGV. E-mail: cristinacgoldschmidt@gmail.com 